\title{
Akne hastalarında yașam kalitesi, problem çözme, kontrol odağı ve öfke eğilimi
}

\author{
Quality of life, problem solving, focus of control and anger tendency in the patients \\ with acne
}

\section{Erman Bağcıoğlu, Bülent Bahçeci*, Ahmet Öztürk**, Erdem Deveci***, Sezai Șașmaz****, Mehmet Fatih Karaaslan******}

Afyon Kocatepe Üniversitesi Tıp Fakültesi, Psikiyatri Anabilim Dalı, Afyonkarahisar, Türkiye *Recep Tayyip Erdoğan Üniversitesi Tıp Fakültesi, Psikiyatri Anabilim Dalı, Rize, Türkiye **Dumlupınar Üniversitesi Tıp Fakültesi, Psikiyatri Anabilim Dalı, Kütahya, Türkiye

***Bezmi-Alem Vakıf Üniversitesi Tıp Fakültesi, Psikiyatri Anabilim Dalı, İstanbul, Türkiye ****Balıkesir Üniversitesi Tıp Fakültesi, Dermatoloji Anabilim Dalı, Balıkesir, Türkiye *****Kahramanmaraș Sütçü İmam Üniversitesi Tıp Fakültesi, Psikiyatri Anabilim Dalı, Kahramanmaraș, Türkiye

\section{Özet}

Amaç: Bu çalışmada akne hastalarının depresyon ve anksiyete düzeyleri, problem çözme, kontrol odağı, öfke eğilimi, yaşam kalitesi düzeyleri ve bunların aknenin klinik özellikleriyle ilişkisinin değerlendirilmesi amaçlandı.

Gereç ve Yöntem: Çalışmamıza akne vulgaris tanısı konmuş 52 kişi ile 46 sağlıklı kontrol dahil edildi. Bütün hastalar, dermatolog tarafından akne şiddetine göre derecelendirildi. Katılımcılara Hamilton Anksiyete Değerlendirme Ölçeği (HAM-A) ve Montgomery-Asberg Depresyon Değerlendirme Ölçeği (MADRS) psikiyatrist (BE) tarafından uygulandı. Kısa Semptom Envanteri (KSE), Problem Çözme Envanteri (PÇE), Sürekli Öfke-Öfke Tarz Ölçeği (SOOTO) ve Rotter'in Iç-Dış Kontrol Odağı Ölçeği (RIDKOÖ) ve SF-36 (Yaşam Kalitesi Kısa Form) uygulandı.

Bulgular: Akne hastalarının depresyon ve anksiyete skorları kontrol grubuna göre anlamlı derecede yüksekti. Kısa semptom envanterinde akne hastalarının anksiyete bozukluğu, depresyon, kişiler arası duyarlıık ve paranoid düşünce skorları kontrol grubundan anlamlı derecede yüksek bulundu. SF-36 ölçeğine göre de fiziksel rol güçlüğü, genel sağlık ve mental sağlık skorları akne hastalarında kontrol grubuna göre anlamlı derecede düşüktü.

Sonuç: Çalışmamızın sonuçları akne vulgarisin depresyon ve anksiyete gibi bazı psikiyatrik problemlere yol açtı̆ı ve hastanın yaşam kalitesini olumsuz olarak etkilediği yönündeki önceki bulguları desteklemektedir. (Türkderm 2014; 48: 177-81)

Anahtar Kelimeler: Akne vulgaris, depresyon, anksiyete, yaşam kalitesi

\section{Summary}

Background and Design: In this study, we evaluated anxiety and depression levels, levels of problem solving, focus of control, tendency to anger and quality of life in patients with acne as well as the association between those parameters and the clinical features of acne. Materials and Methods: Fifty-two patients with mild to severe acne vulgaris and 46 healthy controls were enrolled. Acne severity was graded in all patients by a dermatologist. The Montgomery-Asberg Depression Rating Scale (MADRS), Hamilton Anxiety Rating Scale (HAM-A), Brief Symptom Inventory (BSI), Problem Solving Inventory (PSI), The State-Trait Anger Scale (STAS), Rotter's Internal-External Focus of Control Scale (RIELCS) and the Short Form 36-Item Health Survey (SF-36) were applied to all participants.

Results: In our study, we found out that anxiety and depression scores were significantly higher in patients with acne vulgaris than in controls. In BSI, anxiety disorders, depression, interpersonal sensitivity, and paranoid thoughts scores were significantly higher in patients with acne than in controls. According to SF-36, physical role difficulty, general health and mental health scores were significantly lower in patients with acne. Conclusion: The results of our study support the previous findings suggesting that acne vulgaris leads to various psychiatric problems, such as depression and anxiety and, adversely affects quality of life of patients. (Turkderm 2014; 48: 177-81)

Key Words: Acne vulgaris, depression, anxiety, quality of life

Yazışma Adresi/Address for Correspondence: Dr. Erman Bağcıoğlu, Afyon Kocatepe Üniversitesi Tıp Fakültesi, Psikiyatri Anabilim Dalı, Afyonkarahisar, Türkiye Gsm: +90 5069721449 E-posta: ermanbagcioglu@yahoo.com Geliş Tarihi/Received: 04.06.2013 Kabul Tarihi/Accepted: 18.11.2013 


\section{Giriş}

Fiziksel ve sosyal değişikliklerin en üst düzeyde olduğu ve kimlik gelişiminin yaşandığı ergenlik döneminde ortaya çıkabilen akne kişilerin kaygılarında odak haline gelebilmekte; günlük performansında ve kendisi ile ilgili değerlendirmelerde etkili olabilmektedir1-3. Yaşamı tehdit edici olmamakla birlikte, akne beraberinde anksiyete, depresyon, öfke suisidal düşünce gibi ciddi psikolojik sorunları getirebildiğinden sadece kozmetik bir problem olarak ele alınmaması gerektiği birçok çalışmada bildirilmiştir4-6. Koo ve Smith7 psikojenik etkenlerle akne arasında en az üç türlü etkileşimin olabileceğini öne sürmüştür. Bu etkileşimler, (i) Duygusal stresin akneyi şiddetlendirmesi; (ii) Akneye ikincil olarak hastalarda anksiyete, depresyon, sosyal fobi, düşük benlik saygısı gibi psikiyatrik belirtilerin gelişmesi; (iii) Beden dismorfik bozukluğunda olduğu gibi birincil psikiyatrik bozukluğun akneye odaklaşması şeklinde kendini gösterir.

Akne hastalarında olası psikolojik etkiler sıklıkla aknenin arkasına saklandığından psikiyatriye gitmek gecikmektedir8,9. Oysa akneli bireylerde psikiyatrik komorbidite geniş biçimde tanımlanmışırı10. Anksiyete, depresif bozukluk, özellikle suisidal düşünce ${ }^{11}$, beden dismorfik bozukluğu ve uyum bozukluğu12 akne vulgarisli hastalarda sık rastlanılan psikiyatrik bozukluklardır.

Bu çalışma, akne vulgaris ile psikojenik faktörlerle ilişkisi inceleyen mevcut literatür bilgisini daha da geliştirmek için tasarlandı. Bu çalışmadaki amacımız dermatoloji polikliniğine ayaktan başvuran akne hastalarının sosyo-demografik verilerini incelemek ve aknenin klinik özelliklerinin problem çözme, kontrol odağı ve öfke eğilimi ve yaşam kalitesi ile olan ilişkisini değerlendirmek ve anksiyete, depresyon skorlarını araştırmaktır.

\section{Gereç ve Yöntem}

Çalışmamıza Dermatoloji Polikliniğine ayaktan başvuran 16-28yaşlarında akne vulgarisli 52 olgu ile yaş, cinsiyet, eğitim düzeyi açısından eşleştirilmiş 46 sağlıklı gönüllü alındı. Akne vulgaris hastalarında aknenin şiddeti, dermatolog tarafından hafif, orta ve şiddetli olmak üzere 3 grupta değerlendirildi. Okur-yazar olmayanlar, mental retardasyon, psikotik bozukluk, demans, deliryum ve diğer amnestik bozukluğu olanlar ve ön görüşme sırasında çalışmaya katılmayı reddedenler çalışmaya alınmadı. Yerel Etik Kurulu çalışmayı onayladı. Tüm katılımcılardan bilgilendirilmiş olur alındı. Çalışmaya alınan kişiler için sosyo-demografik özellikleri, aldıkları tanı-tedavi, hastalığın şiddeti, süresi ve yerleşim yerini belirleyen bir form araştırmacılar tarafından tasarlandı. Hastalara Hamilton Anksiyete Değerlendirme Ölçeği (HAM-A) ve Montgomery-Asberg Depresyon Değerlendirme Ölçeği (MADRS) uygulandı. Kısa Semptom Envanteri (KSE), Problem Çözme envanteri (PÇE), Sürekli Öfke-Öfke Tarz Ölçeği (SOOTO), Rotter'in iç-Dış Kontrol Odağı Ölçeği ( RIDKOÖ) ve Yaşam Kalitesi Ölçeğinin (SF-36) hasta tarafından doldurulması istendi.

\section{Hamilton anksiyete değerlendirme ölçeği (HAM-A)}

Çalışmaya alınan olguların anksiyete düzeylerini ve şiddet dağılımını ölçmek amacıyla kullanılan bir ölçektir. Toplam 14 soru içermektedir. Her madde 0-4 arasında, ölçeğin toplam puanı 0-56 arasında değişmektedir. Türkçe formunun geçerliliği ve güvenirliği Yazıcı ve ark. ${ }^{13}$ tarafından yapılmıştır.

\section{Montgomery-asberg depresyon değerlendirme ölçeği (MADRS)}

Depresif belirtileri olan hastaların aynı zamanda bedensel hastalıklarının da olduğu koşullarda uygulanır. Toplam 10 maddeden oluşmaktadır.
Ölçekten alınan en düşük puan 0, en yüksek puan ise 60'dır. Türkçe formunun geçerliliği ve güvenirliği Ozer ve ark. ${ }^{14}$ tarafından yapılmıştır.

\section{Kısa semptom envanteri (KSE)}

SCL-90-R'nin kısa formudur. Verilen cevaplara 0 ile 4 arasında değişen puanlar verilir. Değerlendirme puanı 0 ile 212 arasında değişir. Ölçekte alınan toplam puanların yüksekliği, bireyin semptomlarının sıklığını gösterir. Ölçeğin Türkçe'ye uyarlaması Şahin ve Durak15 tarafından yapılmıştır.

\section{Problem çözme envanteri (PÇE)}

Otuz beş maddeden oluşan bir envanterdir. Ölçeğin ölçtüğü genel nitelik, bireyin problem çözme konusunda kendini algılayışının nasıl olduğuna yöneliktir. Ölçekten alınan toplam puanların yüksekliği, bireyin problem çözme becerileri konusunda kendini yetersiz olarak algılandığını göstermektir. Türkçe'ye uyarlaması Şahin ve ark.16 tarafından yapılmıştır.

\section{Sürekli öfke-öfke tarz ölçeği (SOOTO)}

Ölçek sürekli öfke, öfke içte, öfke-dışa ve öfke kontrol alt ölçeklerinden oluşur. Sürekli öfke alt ölçeğinden alınan yüksek puanlar öfke düzeyinin düşük olduğunu, öfke kontrol alt ölçeğindeki yüksek puanlar yüksek öfke kontrol düzeyini, öfke-dışa alt ölçeğindeki yüksek puanlar öfkenin kolayca ifade edilebilir olduğunu ve öfke-içte alt ölçeğindeki puanlar ise öfkenin bastırılmış olduğunu göstermektedir. Türkçe'ye uyarlaması Ozer ve ark. ${ }^{17}$ tarafından yapılmıştır.

\section{Rotter'in iç-dış kontrol odağı ölçeği ( RiDKOÖ)}

Yirmi dokuz maddeden oluşan ölçekte her maddede a ve b harfleriyle gösterilen iki seçenek bulunmaktadır. Ölçekten alınan toplam puan 0-23 arasında değişmektedir. Yükselen puanlar bireyin dış kontrol odağı inancında artış gösterdiğini, düşen puanlar ise bireyin iç kontrol odağına sahip olduğunu göstermektedir. İç kontrol odağı inancında olan kişiler kendi yaşadığı ya da başına gelen hadiselerin kendi davranışlarının sonucu olduğuna inanırken, dış kontrol odağı inancı olan kişiler olayları şans ya da kader gibi dış faktörlerin belirlediğine inanırlar. Türkçe'ye uyarlanması Dağ18 tarafından yapıımıştır.

\section{Yaşam kalitesi ölçeği kısa form (SF-36)}

Fiziksel fonksiyon, sosyal fonksiyon, fiziksel rol güçlüğü, emosyonel rol güçlüğü, mental sağlık, enerji, ağrı ve sağlığın genel algılanması başlıklarında 8 boyutun ölçümünü sağlayan 36 maddeden oluşmaktadır. Alt ölçekler sağlığı 0-100 arasında değerlendirir ve 0 kötü sağlık durumunu gösterir. Bu ölçeğin bedensel hastalığı olanlarda yaşam kalitesinin değerlendirilmesinde kullanılabileceği bildirilmektedir. SF-36'nın Türkçe'ye uyarlanması, geçerlilik ve güvenirlik çalışması Koçyiğit'19 tarafından gerçekleştirilmiştir.

\section{İstatistik}

Çalışmanın istatistiği "SPSS 13.0" programı kullanılarak yapıldı. Oranların karşılaştıııması için Ki-kare testi, ikili ortalamaların karşılaştırılması için Student-t testi uygulandı. Sonuçlar $p<0,05$ ise anlamlı kabul edildi. Bağıntı analizi için Spearman bağıntı analizi kullanıldı.

\section{Bulgular}

Hasta grubu 46 kadın 6 erkek, kontrol grubu ise 39 kadın 7 erkekten oluşmakta idi. Cinsiyet açısından gruplar arasında bir farklıık yoktu $(p=0,592)$. Hasta grubunun yaş ortalaması $20,53(s d=3,71)$, kontrol grubunun yaş ortalaması $20,76(\mathrm{sd}=3,47)$ olup iki grup arasında istatiksel olarak anlamlı bir farklılık yoktu $(p=0,922)$. Her iki grup medeni durum açısından karşılaştııılığında hasta grubunda 45 bekar, 
7 evli, kontrol grubunda 37 bekar ve 7 evli bulunmakta idi. Medeni durum açısından iki grup arasında anlamlı bir farklılık bulunmamaktaydı $(p=0,415)$. Eğitim durumları incelendiğinde, hasta grubunda 3 kişi ilkokul mezunu, 14 kişi ortaokul, 29 kişi lise ve 6 kişi yüksekokul mezunu idi. Kontrol grubunda ise 1 kişi ilkokul, 1 kişi ortaokul, 29 kişi lise ve 15 kişi yüksekokul mezunuydu. Her iki grup arasında eğitim düzeyi açısından farklılık olup, kontrol grubunda yüksek okul mezunu olanların sayısının fazla olmasından kaynaklanmakta idi $(p=0,001)$. Çalışma grubumuzdaki olguların 23'ünde $(\% 44,2)$ aknenin yerleşim yeri yüz, 29'unda $(\% 55,8)$ yüz ve gövde idi. Lezyon şiddetine göre hafif derecede akneli 21 $(\% 40,4)$, orta derecede akneli $22(\% 42,3)$, şiddetli akneli ise $9(\% 17,3)$

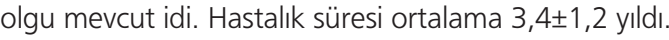

Akneli hastalarda Hamilton anksiyete skoru ve Montgomery-Asberg depresyon skoru kontrol grubuna göre anlamlı derecede yüksek bulundu ( $p=0,019, p=0,006$, sırasıyla) (Tablo1). Genel olarak her iki grubun, kısa semptom envanteri alt ölçekleri değerlendirildiğinde, akne grubunda anksiyete bozukluğu $(p=0,034)$, depresyon $(p=0,008)$, kişilerarası duyarlıık $(p=0,047)$ ve paranoid düşünce $(p=0,043)$ skorları kontrol grubuna göre istatistiksel olarak yüksek bulundu (Tablo 2). Akneli hastalar sürekli öfke-öfke tarz ölçeğinin alt ölçekleri değerlendirmesinde sürekli öfke, öfke içte, öfke dışta ve öfke kontrol puanları bakımından kontrol grubundan farklı bulunmadı (Tablo 3). Akneli hastalar ve kontrol grubu arasında toplam problem çözme puanları açısından anlamlı bir sonuç bulunmadı (Tablo 4). Yine akne ve kontrol grubu arasında problem çözme envanteri alt ölçekleri olan aceleci yaklaşım $(p=0,753)$, düşünen yaklaşım ( $p=0,628)$, kaçıngan yaklaşım $(p=0,575)$, değerlendirici yaklaşım ( $p=0,372)$, kendine güvenli yaklaşım $(p=0,359)$ ve planlı yaklaşım $(p=365)$ bakımından da istatistiksel olarak anlamlı bir sonuç bulunmadı. Akne ve kontrol gruplarında, Rotter Kontrol Odağı Ölçeği (RKOO) puanları açısından da anlamlı bir fark olmadığı tespit edilmiştir (Tablo 4). Akneli hastalar ve sağlıklı gönüllüler yaşam kalitesi (SF-36) açısından karşılaştırılığında, fiziksel rol güçlüğü $(p=0,003)$, genel sağlık $(0,018)$ ve mental sağlık $(p=0,017)$ alt boyutlarında anlamlı farklılık bulunmaktaydı (Tablo 5).

\section{Tartışma}

Çalışmamızda anksiyete ve depresyon skorları akne vulgarisli bireylerde daha yüksek bulunmuştur. Bir çok çalışma akne vulgarisli hastaların anksiyete ve depresyon skorlarını genel popülasyondan daha yüksek bulmuştur20,21. Akne vulgaris astım, diyabet, artrit ve koroner arter hastalığı ile kıyaslandığında akneli hastalarda daha fazla ruhsal hastalık görüldüğünü hatta psoriasisden daha yüksek anksiyete ve depresyon skorlarına sahip olduğunu vurgulayan çalışmalar vardır22-24. Bunun yanında, akneli hastalarda anksiyete ve depresyon düzeyinin değişmediğini öne süren çalışmalar da bulunmaktadır25,26. Özcan ve ark.27 akne vulgarisli hastaları sağlıklı kontrollerle karşılaştırmış, kaygı ve depresyon düzeyinde istatistiksel olarak anlamlı bir sonuç saptanmamıştır. Depresyon ve anksiyete düzeyinin yüksek çıkması beklenirken çıkan bu sonuç, psikosomatik hastalıkların gelişiminde önemli rol oynadığı düşünülen aleksitimi ile açıklanılmaya çalışılmıştır. Bizim çalışmamız akne hastalarında anksiyete ve depresyon skorlarının yüksek olduğunu bildiren çalışmaların sonucunu desteklemektedir. Aknenin klinik şiddetinin, hastalığın neden olduğu psikiyatrik bozuklukların şiddeti ile uyum içerisinde olup olmadığını araştıran çalışmaların sonuçları çelişmektedir. Niemeyer ve ark. ${ }^{20}$ çalışmalarında akne şiddeti ve psikososyal stres ile arasında ilişki saptamamışlardır. Lim ve $\operatorname{Tan}^{28}$ ise akne şiddeti ve nevrotik değerler arasında anlamlı bir ilişki bulmuştur. Wu ve ark. 29 ile Hull ve ark. 30 da akne şiddeti ile depresyon ve anksiyete seviyeleri arasında direkt bir ilişki saptamamıştır. Biz ise çalışmamızda akne şiddeti ile depresyon ve anksiyete skorları arasında anlamlı bir korelasyon bulamadık. Bu çelişkili sonuçlar bu alanda daha fazla veriye gereksinim olduğunu, başka değişkenlerin de var olabileceğinin göz önünde bulundurulması gerektiğini ortaya koymaktadır.

Tablo 1. Akne vulgarisli hastaların ve kontrol grubunun ansksiyete ve depresyon skorları

\begin{tabular}{|l|l|l|l|l|}
\hline & Akne grubu & Kontrol grubu & t & $\mathbf{p}$ \\
\hline HAM-A & $11,86 \pm 8,71$ & $8,36 \pm 5,04$ & 2,389 & ${ }^{*} 0,019$ \\
\hline MADRS & $14,25 \pm 9,62$ & $9,39 \pm 7,16$ & 2,805 & $* 0,006$ \\
\hline \multicolumn{2}{|l|}{ Ort: Ortalama, SS: Standart sapma, HAM-A: Hamilton Anksiyete Değerlendirme Ölçeği, MADRS: Montgomery-Asberg Depresyon Değerlendirme Ölçeği } \\
\hline
\end{tabular}

Tablo 2. Akne ve kontrol grubunun kısa semptom envanteri alt ölçeklerinin karşılaştırılması

\begin{tabular}{|c|c|c|c|c|}
\hline & Akne grubu & Kontrol grubu & $\mathbf{t}$ & $\mathbf{p}$ \\
\hline Somatizasyon & $6,00 \pm 5,82$ & $5,06 \pm 5,30$ & 0,827 & 0,411 \\
\hline Obsessive kompulsive bozukluk & $8,03 \pm 5,11$ & $7,06 \pm 4,96$ & 0,953 & 0,343 \\
\hline Depresyon & $8,53 \pm 6,61$ & $5,41 \pm 4,54$ & 2,691 & ${ }^{\star} 0,008$ \\
\hline Anksiyete bozukluğu & $7,19 \pm 5,49$ & $5,04 \pm 4,24$ & 2,145 & ${ }^{*} 0,034$ \\
\hline Paranoid düşünce & $7,11 \pm 4,96$ & $5,28 \pm 3,67$ & 2,055 & ${ }^{*} 0,043$ \\
\hline Psikotizim & $4,82 \pm 3,81$ & $4,08 \pm 3,38$ & 1,010 & 0,315 \\
\hline Ek maddeler & $4,90 \pm 4,33$ & $3,89 \pm 2,83$ & 1,350 & 0,180 \\
\hline Rahatsızlık ciddiyet indeksi & $57,45 \pm 39,92$ & $44,46 \pm 30,25$ & 1,797 & 0,075 \\
\hline
\end{tabular}


Kısa semptom envanterinde, akneli hastalarda depresyon, anksiyete, kişilerarası duyarlıık, paranoid düşünce skorlarını sağlıkı kontrollerden anlamlı derecede yüksek bulduk. Paranoid düşünce ve kişilerarası duyarlıık skorunun akneli hastalarda yüksek olmasını, yüzdeki olumsuz görünümün vücut imajı algısında bozulma, öz saygıda azalma gibi olumsuz duygulara itmesi bununda beraberinde sosyal geri çekilme ve kişilerarası ilişkilerde, dikkatlerin aknesine odaklandığı düşüncesini beraberinde getirmesi olarak yorumladık. Phillips, dismorfik bozukluğun genellikle adolesan dönemde başladığından, akne lezyonlarının beden dismorfik bozukluk gelişimi için predispozan olabileceğini bildirmiştir31 Kellet ve Gawrodger23 akne hastalarının görünümleriyle ilgili negatif ve utanç tutumlarının lezyonların azaldığı dönemde bile sürdüğünü bildirmiştir. Beden dismorfik bozukluğuna akne ekskoriye olgularında daha sık rastlanılmıştır32.

Çalışmamızda akneli hastalar, öfke alt ölçekleri puanları bakımından kontrol grubundan farklı bulunmadı. Kardiovasküler hastalıklar, osteoporoz, artrit, tip 2 diyabet ve bazı kanserlerde öfke eğilimi, düşük yaşam kalitesi ve daha şiddetli hastalık ile ilişkili bulunmuştur33,34. Şiddetli aknesi olan hastalarda, hafif şiddetli aknelilere göre daha yüksek öfke skoru bulunmuş ve öfkenin akne şiddetini etkileyebileceği bildirilmiştir29. Sayar ve ark. Spielberger Durumsal ve Sürekli Öfke İfadesi Envanteri ile yaptıkları çalışmada akne ve kontrol grubu arasında öfkeyle ilgili alt ölçeklerde bir farklılık bulamamışlardır35. Elde ettiğimiz sonuçlar akne şiddeti ve öfke arasında bir ilişki olmadığını ve aknenin neden olduğu psikolojik sürece öfke eğiliminin direkt bir etki yapmadığını göstermektedir. Kişilik boyutlarından kontrol odağı, iç ve dış yönelim olmak üzere, kişinin yaşadığı ya da başına gelen olayların kendi davranışlarının sonucu olarak ya da başka dış güçler tarafından belirlendiği inancıdır ${ }^{18}$. Çalışmamızda, akne hastaları ve kontrol grubu arasında kontrol odağı toplam puanında anlamlı bir fark bulunmamıştır. Evans ve ark. 36 kronik hastalıklarda dış kontrol odağı inancının depresif belirtileri etkileyebileceğini ve ümitsizlik duygusu ile stres yaşantısına neden olabileceğini ileri sürmüştür. Amacımız akneli hastalardaki somatopsişik belirtilere, kişilik özellikleriyle ilişkili olan kontrol odağı algısının, yatkınlaştıııı bir etmen olup olmadığını araştırmaktı. Şimdiye kadar akneli hastalarda kontrol odağı ile yapılmış bir çalışma bulunmamaktadır. Kişilik ve akne arasında bir ilişki olup olmadığı konusunda da kesin bir bilgi henüz bulunmadığından bu araştırmanın bu doğrultuda katkı sağlayabileceği düşünülmüştür. Çalışmamızda akneli ve kontrol grubu arasında toplam problem çözme puanları arasında istatistiksel olarak anlamlı bir ilişki bulunmamıştır. Etkisiz problem çözmenin stresli yaşam olaylarını tetiklediği ve psikolojik uyumsuzluk getirdiği bildirilmiştir37. Birçok çalışma problem çözme yetersizliğinin depresyon ve suisid girişiminde önemli rol oynadığı gösterilmiştir38. Kaçıngan, narsist, bağımlı ve borderline kişilik bozukluğu olan depresif hastaların, kişilik bozukluğu olmayan depresif hastalara göre daha kötü sorun çözme yetisi gösterdikleri gözlemlenmiştir39. Akne hastalarının kontrol grubuna göre daha kötü problem çözme becerisi göstereceklerine ilişkin hipotezimizin aksine akne ve kontrol grubu arasında anlamlı bir fark bulunmadı. Bu konuda daha kapsamlı çalışmalar gerekmektedir.

Diğer bir bulgumuz akne hastalarında SF-36 ölçeğine göre fiziksel rol güçı̈̈̆ü, genel sağlık ve mental sağlık skorları kontrol grubundan anlamlı derecede düşük bulunmasıydı. Aknede yaşam kalitesini değerlendirmek için hem genel ölçekler hem de akneye özgü ölçekler

Tablo 3. Akne ve kontrol grubunun sürekli öfke-öfke tarz ölçek puanlarının karşılaştırılması

\begin{tabular}{|l|l|l|l|l|}
\hline & Akne grubu & Kontrol grubu & t & p \\
\hline Sürekli öfke & $22,15 \pm 7,14$ & $22,00 \pm 5,38$ & 0,193 & 0,947 \\
\hline Öfke içte & $16,44 \pm 4,32$ & $16,97 \pm 4,23$ & $-0,613$ & $0,5,38$ \\
\hline Öfke dışta & $15,84 \pm 5,33$ & $17,13 \pm 4,64$ & $-1,264$ & 0,209 \\
\hline Öfke kontrol & $20,96 \pm 4,78$ & $20,04 \pm 5,10$ & 0,919 & 0,361 \\
\hline
\end{tabular}

Tablo 4. Akne ve kontrol grubunun toplam problem çözme puanlarının ve rotter kontrol odağı toplam puanlarının karşılaştırılması

\begin{tabular}{|l|l|l|l|l|}
\hline & Akne grubu & Kontrol grubu & t & p \\
\hline Toplam problem çözme puanı & $104,78 \pm 14,71$ & $105,06 \pm 17,17$ & 0,86 & 0,932 \\
\hline Kontrol odağı toplam puanı & $11,00 \pm 3,23$ & $10,34 \pm 4,01$ & 0,890 & 0,376 \\
\hline
\end{tabular}

Tablo 5. Akne ve kontrol grubunun SF-36 alt ölçek skorlarının karşılaştırılması

\begin{tabular}{|c|c|c|c|c|}
\hline & Akne grubu & Kontrol grubu & $\mathbf{t}$ & p \\
\hline Fiziksel fonksiyon & $82,98 \pm 18,53$ & $84,45 \pm 15,81$ & $-0,421$ & 0,675 \\
\hline Fiziksel rol güçlüğü & $57,69 \pm 32,28$ & $77,71 \pm 33,84$ & 2,996 & ${ }^{\star} 0,003$ \\
\hline Genel sağlık & $53,65 \pm 16,32$ & $61,97 \pm 17,97$ & $-2,403$ & ${ }^{\star} 0,018$ \\
\hline Vitalite & $52,11 \pm 20,44$ & $57,60 \pm 16,72$ & $-1,444$ & 0,152 \\
\hline Mental sağlık & $52,53 \pm 19,43$ & $62,60 \pm 16,00$ & $-2,778$ & ${ }^{*} 0,007$ \\
\hline
\end{tabular}


kullanılmıştır. Bu değişik ölçeklerle yapılan sonuçları değerlendirmek güç olsa da aknenin yaşam kalitesini olumsuz yönde etkilediği konusunda mutabakat vardır40,28. Skindex yaşam ölçeğinin, 60 akneli hastaya uygulandığı bir araştırmada emosyonel ve fonksiyonel alt ölçeklerde psoriasisli hastalara benzediği ama düşük fiziksel semptomların olduğu bildirilmiştir41. Mallon ve ark.'nın40,111 akneli hastada yaşam kalitesini SF-36 ile diğer organik hastalıklara sahip kişilerle karşılaştırdıkları çalışmalarında; akne hastalarının sosyal, emosyonel ve psikolojik problemlerinin astım, epilepsi, diyabet ve artrit kadar ciddi olduğunu saptamışlardır. Ülkemizde aknenin yaşam kalitesi üzerine olan etkisini SF-36 ile değerlendiren bir çalışmada 73 akneli hasta, 48 kontrol grubuyla karşılaştırımıştır. Bu çalışmada akne ve kontrol grubu fiziksel fonksiyon dışında diğer parametrelerde benzerlikler göstermiştir. Akneli hastaların fiziksel fonksiyon skorları kontrol grubundan daha düşük bulunmuştur42.

\section{Sonuç}

Bulgularımız akne hastalarının sadece kozmetik açıdan değerlendirilmemesi gerektiğini anksiyete ve depresif bozukluk gibi ciddi psikiyatrik hastalıkların görülebileceğini, kişiler arası duyarlılığın artabileceğini bundan dolayı bireyde sosyal geri çekilmenin olabileceği ve yaşam kalitesinin etkilenebileceğini ortaya koymaktadır. Akne hastalarının sosyal destek gereksinimi göz önünde bulundurmak ve tedaviye multidisipliner olarak yaklaşım önemli gözükmektedir.

\section{Kaynaklar}

1. Hanna S, Sharma J, Klotz J: Acne vulgaris: more than skin deep. Dermatol Online J 2003;9:8.

2. Khan MZ, Naem A, Mufti KA: Prevelance of mental health problems in acne patients. J Ayub Med Coll Abbottabad 2001;13:7-8.

3. Rubinow DR, Peck GL, Squillanve K, Gantt GG: Reduced anxiety and depression in cystic acne patients after succesful treatment with oral isotretinoin. J Am Acad Dermatol 1987;17:25-32.

4. Magin P, Adams J, Heading G, Pond D, Smith W: Psychological sequelae of acne vulgaris: results of a qualitative study. Can Fam Physician 2006;52:9789.

5. Purvis D, Robinson E, Merry S, Watson P: Acne, anxiety, depression and suicide in teenagers: a cross sectional survey of New Zealand secondary school students. J Paediatr Child Health 2006;42:793-6.

6. Rapp DA, Brenes GA, Feldman SR, Fleischer AB, Gram GF, Daily M: Anger and acne: implications for quality of life, patient satisfaction and clinical care. Br J Dermatol 2004;151;183-9.

7. Koo JY, Smith LL: Psychologic aspect of acne. Pediatr Dermatol 1991;8:185-8.

8. Picardi A, Abeni D, Melchi CF, Peddu P, Pasquini P: Psychiatric morbidty in dematological outpatients: an issue to be recognized. $\mathrm{Br} J$ Dermatol 2000;143:983-91.

9. Kramer T, Garralda ME: Psychiatric disorders in adolescents in primary care. Br J Psychiatr 1998;173:508-13.

10. Gupta MA, Gupta AK: The psychological comorbidity in acne. Clin Dermatol 2001;19:360-3.

11. Picardi A, Mazotti E, Pesquini P: Prevalence and correlates of suicidal ideation among patients with skin disease. J Am Acad Dermatol 2006;54:420-6.

12. Phillips KA, Dufresne RG Jr, Wilkel CS, Vittorio CC: Rate of body dysmorphic disorder in dermatology patients. J Am Acad Dermatol 2000;42:436-41.

13. Yazııı MK, Demir B, Tanriverdi N, Karaağaoğlu E, Yolaç P: Hamilton Anksiyete Değerlendirme Ölçeği: Değerlendiriciler arası güvenirlik ve geçerlik çalışması. Turk Psikiyatri Derg 1998;9:114-7.

14. Ozer S, Demir B, Tuğal O, Kabacı E, Yazıcı MK: Montgomery-Asberg Depresyon Değerlendirme Ölçeği: Değerlendiriciler arası güvenirlik ve geçerlilik çalısması. Turk Psychiatri Derg 2001;12:185-94.
15. Sahin NH, Durak A: Kısa Semptom Envanteri. Türk gençleri için uyarlanması. Türk Psikoloji Dergisi 1994;9:44-56.

16. Sahin N, Sahin NH, Heppner P: Psychometric properties of the problem solving inventory in a group of Turkish university students. Cognit Ther Res 1993;17:379-96

17. Ozer AK: Surekli Öfke ve öfke tarz ölçekleri ön çalışması. Türk Psikoloji dergisi 1994;31:26-35.

18. Dağ. Rotter'in iç-dış kontrol odağı ölçeğinin (RiDKOÖ. üniversite öğrencilerinde güvenirlik ve geçerlilik. Psikoloji Dergisi 1991;7(26::10-6

19. Koçyiğit $H$, Aydemir Ö, Ölmez N, ve ark: SF-36'nın Türkçe için güvenilirliği ve geçerliliği. ilaç ve tedavi 1999;12:102-6.

20. Niemeier V, Kupfer J, Demmelbauer-Ebner M, Stangier U, Effendly I, Gieler U: Coping with acne vulgaris. Evaluation of chronic skin disorder questionnaire in patients with acne. Dermatology 1998;196:108-15.

21. Aktan S, Ozmen E, Yavuz Ş, Özkaya N: The psychiatric symptoms in patients with acne vulgaris. Turkderm 1994;28:93-8.

22. Gupta MA, Gupta AK: Depression and suicidal ideation in dermatology patients with acne, alopecia areata and psoriasis. $\mathrm{Br} J$ Dermatol 1998; 139;846-50.

23. Kellet SC, Gawkrodger DJ: The psychosocial and emotional impact of acne and the effect of treatment with isotretionin. Br J Dermatol 1999;140:27382.

24. Tan JK: Psychosocial impact of acne vulgaris: evaluating the evidence. Skin Therapy Lett 2004;9:1-3.

25. Aktan S, Ozmen E, Sanli B: Anxiety, depression and nature of acne vulgaris in adolescents. Int J Dermatol 2000;39:354-7.

26. Myhill JE, Leichtman SR, Burnett JW: Self-esteem and social assertiveness in patients receiving isotretinoin treatment for cystic acne. Cutis 1988;41:171 3.

27. Ozcan Y, Ozcan $H$, Unal S: Akne vulgarisli bireylerde kişilik özellikleri. Klinik Psikiyatri 2000;3:56-60.

28. Lim CC, Tan TC: Personality, disability and acne in college students. Clin Exp Dermatol 1991;16:371-3.

29. Wu SF, Kinder BN, Trunnell TN, Fulton JE: Role of anxiety and anger in acne patients: a relationship with the severity of the disorder. J Am Acad Dermatol 1988; 18:325-32.

30. Hull SM, Cunliffe WJ, Hughes BR: Treatment of the depressed and dysmorphophobic acne patient. Clin Exp Dermatol 1991;16:210-1.

31. Phillips KA: The Broken mirror: Understanding and Treating body Dysmorphic Disorder. New York, NY: Oxford University press. 2005.

32. Gupta MA, Gupta AK, Schork NJ: Psychological factors affecting self excoriative behavior in women with mild-to-moderate facial acne vulgaris. Psychosomatics 1996;37:127-30.

33. Smith TW, Ruiz JM: Psychosocial influences on the development and course of coronary heart disease: current status and implications for research and practice. J Consult Clin Psychol 2002;70:548-68.

34. Kliecolt-Glaser JK, Mc Guire L, Robles TF, Glaser R: Psychoneuroimmunology: psychological influences on immune function and health. J Consult Clin Psychol 2002;70:537-47.

35. Sayar K, Ugurad I, Kural Y, Acar B: The psychometric assessment of acne vulgaris patients. Dermatology and Psychosomatics 2000;1:62-5.

36. Evans RW, Manninen DL, Garrison LP Jr, et al: The quality of life of patients with end stage renal disease. N Engl J Med 2000;312;553-9.

37. D'Zurilla TJ: Problem-solving therapy: a social competence approach to clinical intervention. Springer. New York.1986

38. Eskin M, Ertekin K, Harlak H, Dereboy C: Prevalence of and factors related to depression in high school students. Türk Psikiyatri Derg 2008;19:382-9.

39. Harley R, Petersen T, Scalia M, Papacostas Gl, Farabaugh A, Fava M: Problemsolving ability and comorbid personality disorders in depressed outpatients. Depression and Anxiety 2006;23:496-501.

40. Mallon E, Newton JN, Klassen A, Stewart-Brown SL, Ryan TJ, Finlay AY: The quality of life in acne: a comparison with general medical conditions using generic questionnaires. Br J Dermatol 1999;140:672-6.

41. Lasek RJ, Chren MM: Acne vulgaris and the quality of life of adult dermatology patients. Arch Dermatol 1998;134:454-8.

42. Ozturkcan S, Aydemir O, Inanir I: Acne vulgarisli hastalarda yaşam kalitesi. T Klin J Dermatoloji 2002;12:131-4. 